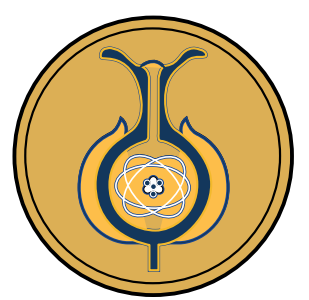

\title{
Análisis multitemporal de asociaciones vegetales y cambios de uso del suelo en una localidad altoandina, Puno-Perú
}

\author{
Multitemporal analysis of plant associations and land use changes in a high \\ Andean locality, Puno-Peru
}

Análise multitemporal de associações vegetais e mudanças de uso do solo em uma localidade altoandina, Puno-Peru

Alfredo Loza-Del Carpio ${ }^{1}$ Irene Taype-Huamán ${ }^{1}$

Received: Jun/22/2020 • Accepted: Nov/24/2020 • Published: Jul/31/2021

\section{Resumen}

En los altos Andes se vienen evidenciando cambios no planificados de uso de territorios que conllevan a pérdida de áreas productivas y de importantes servicios ecosistémicos; documentando ese contexto, el objetivo de este estudio fue caracterizar los cambios temporales en la vegetación y uso del suelo en el distrito altoandino de Cabana (Perú). Se determinó el tipo de vegetación según la especie predominante en la cobertura; estas áreas, conjuntamente con las formas de uso de suelo frecuentes, se cuantificaron mediante análisis supervisado de imágenes Landsat con una resolución espectral de 30 m, obtenidas en los meses de marzo y abril de los años 2000, 2005, 2010 y 2016. Se identificaron seis tipos de asociaciones vegetales naturales cuyas áreas disminuyeron 2000 ha, de las 12500 iniciales en 16 años (16,27\%); al año 2000 la asociación Muhlenbergetum fastigiatae tuvo la mayor cobertura (43,96 \%), pero en 2016 predominó Calamagrostio vicunaro - Festucetum dolichophyllae (47,31\%). Las áreas de cultivo aumentaron desde 5133 ha (27\%) a 7115 ha (37 \%) de la superficie distrital; se extendieron suelos degradados desde 35 a 120 ha, áreas con escasa vegetación de 17 a 30 ha y se redujeron humedales de 179 a 29,7 ha. La cobertura urbana crece a un 40,7\% anual. El aprovechamiento del suelo, sin base en un ordenamiento territorial, condujo al detrimento de la vegetación, y comprometió el aprovechamiento sostenible de recursos naturales.

Palabras clave: Imágenes satelitales; vegetación; degradación; cultivos; altiplano

\section{Abstract}

Unplanned changes in the use of high Andean territories have become more evident, leading to a loss of productive areas and important ecosystem services. Under this context, the objective of this study was to characterize the temporal changes in vegetation and land use in the high Andean district of Cabana (Peru). Vegetation types were determined based on the predominant species; these areas, together with the frequent forms of land use, were quantified using a supervised analysis of Landsat images with a 30 m spectral resolution,

Alfredo Loza-Del Carpio, $\$ allozadc@yahoo.es, D https://orcid.org/0000-0003-4915-1152

Irene Taype-Huamán, $\triangle$ yastaipe@gmail.com, (D) https://orcid.org/0000-0002-1910-0111

1 Programa de Ecología de la Facultad de Ciencias Biológicas, Universidad Nacional del Altiplano, Puno, Perú. 
obtained during March and April 2000, 2005, 2010, and 2016. Six types of plant associations were identified whose areas decreased $2000 \mathrm{ha}$, from the initial 12500 in 16 years (16.27\%). By 2000 the Muhlenbergetum fastigiatae association had the highest coverage (43.96\%), but in 2016 Calamagrostio vicunaro - Festucetum dolichophyllae predominated (47.31\%). Crop areas increased from 5133 ha (27\%) to 7115 ha (37\%) of the district surface, while degraded soils extended from 35 to $120 \mathrm{ha}$, sparsely vegetated areas from 17 to 30 ha and wetland reduced from 179 to 29.7 ha. Urban coverage grew $40.7 \%$ annually. Land use with no territorial ordering basis caused detriment in vegetation and compromised the sustainable use of natural resources.

Keywords: satellite images; vegetation; degradation; crops; plateau

\section{Resumo}

Nos altos Andes vêm se tornando evidente as mudanças não planejadas do uso de territórios, desencadeando perdas de áreas produtivas e de importantes serviços ecossistêmicos. 0 objetivo deste estudo, ao documentar esse contexto, foi caracterizar as mudanças temporais na vegetação e no uso de solo no distrito altoandino de Cabana (Peru). Foi determinado o tipo de vegetação de acordo com a espécie predominante na cobertura. Estas áreas, juntamente com as formas de uso de solo frequentes, foram quantificadas por meio de uma análise supervisionada de imagens Landsat com uma resolução espectral de $30 \mathrm{~m}$, obtidas nos meses de março e abril dos anos 2000, 2005, 2010 e 2016. Foram identificados seis tipos de associações vegetais naturais cujas áreas reduziram 2000 ha, das 12500 iniciais em 16 anos (16,27\%); no ano 2000, a associação Muhlenbergetum fastigiatae teve a maior cobertura (43,96\%), porém, em 2016 predominou a Calamagrostio vicunaro - Festucetum dolichophyllae (47,31\%). As áreas de cultivo aumentaram de 5133 ha (27\%) a 7115 ha (37\%) da superfície distrital; estenderam-se solos degradados de 35 a 120 ha, áreas com escassa vegetação de 17 a 30 ha e houve uma redução das áreas úmidas de 179 a 29,7 ha. A cobertura urbana cresce $40,7 \%$ anualmente. 0 aproveitamento do solo, sem base em um ordenamento territorial, conduziu ao detrimento da vegetação e comprometeu o aproveitamento sustentável de recursos naturais.

Palavras-chave: Imagens satelitais; vegetação; degradação; cultivos; altiplano

\section{INTRODUCCIÓN}

Las continuas transformaciones de los ecosistemas por actividades antropogénicas, asociadas a un inadecuado usufructo de los recursos naturales, vienen afectando negativamente la vegetación natural (Molles, 2006), y han conllevado a procesos de erosión, degradación y desertificación de los suelos, al punto de que cada año en el mundo seis millones de hectáreas se convierten en desiertos (Smith y Smith, 2001) y 20 millones de hectáreas al año pierden parcialmente su capacidad para actividades agrícolas y ganaderas (Granados-Sánchez et al., 2013). Esta situación afecta especialmente los ecosistemas andinos, conjuntamente con una alarmante reducción de cauces fluviales, pérdida de recursos naturales, biodiversidad y fuerte presión de uso sobre los hábitats (FAO, 2014), al punto que entre el 2000 y 2012, en Sudamérica se perdieron $14459 \mathrm{~km}^{2}$ de superficie de ecosistemas tropicales de montaña (Hansen et al. 2013).

Se ha considerado que el uso del territorio es un problema local, sin embargo, se ha convertido en una fuerza de trascendencia mundial (Foley et al., 2005). Los cambios en el uso de la tierra y la cobertura alteran considerablemente el balance energético y 
los ciclos biogeoquímicos, al contribuir con el cambio climático y limitar la provisión de servicios ecosistémicos (Song et al., 2018); además, la transgresión sustancial y persistente de la integridad de la biósfera puede llevar al sistema terrestre a un nuevo estado desconocido (Steffen et al., 2015) y el $60 \%$ de estos cambios están asociados a actividades humanas, principalmente a la deforestación tropical, a la expansión agrícola y a la urbanización (Song et al., 2018).

La cubierta vegetal natural beneficia directa e indirectamente a las sociedades humanas y sus cambios afectan la capacidad de los ecosistemas para sostener la producción de alimentos, mantener recursos forestales, suministro de agua, regulación del clima, calidad del aire y atenuar enfermedades infecciosas (Foley et al., 2005; Hansen et al., 2013). Previene también las inundaciones, participa en el reciclaje y almacenamiento del agua, mejora la filtración del suelo, reduce la erosión y atrapa sedimentos y contaminantes con lo cual mejora la calidad del agua (Hamilton et al., 2009; CIFOR, 2013). Su disminución repercute en el cambio climático y en los productos de la biodiversidad (alimentos, medicinas) (Hansen et al., 2013; Gil-Leguizarrón y Morales-Puentes, 2016). La vegetación natural es también un agente reductor de contaminación atmosférica y del ruido, provee bienestar espiritual y cultural por su valor estético, recreativo y educativo (Metteuci y Colma, 1982).

Evaluar los cambios multitemporales en la vegetación permite entender las causas $\mathrm{y}$ efectos en las condiciones del ambiente y apertura de mejores posibilidades para un aprovechamiento sostenible del espacio y de los recursos naturales; además, es esencial para comprender las interacciones ser humano - naturaleza (Aly et al., 2016). Su mejor conocimiento también proporciona fundamentos para el manejo de bosques, pastizales y territorios y sus cambios sirven de indicadores de la eficiencia y de los efectos del manejo o de algún tipo de uso (Matteuci y Colma, 1982). Los análisis de vocación de los ecosistemas parten de conocer las características del suelo y de su fitocenosis asociada, lo cual conlleva a establecer criterios integrales para la correcta planificación y manejo del territorio (Cotler et al., 2007), así como el reconocimiento de su auténtico potencial productivo para mantener en el tiempo sus beneficios (Villalta y Castaneda, 2003; Ríos et al., 2015; FAO, 2018).

Este contexto está escasamente documentado y estudiado en pisos ecológicos del altiplano peruano por encima de $\operatorname{los} 3800$ $\mathrm{msnm}$. Aunque un estudio previo, en una comunidad a orillas del Titicaca, ya ha reportado una pérdida de cobertura vegetal nativa de $16,8 \%$ (2 686 ha) y un incremento de suelo desnudo en $12,29 \%$ (1 969 ha) en un lapso de 10 años (Condori-Castillo, 2012), antecedente que evidencia el alarmante escenario ecológico de la zona altoandina con respecto al uso del territorio. No se cuenta con reportes similares en ambientes aún más altos, como la puna o la cordillera, por lo que el distrito de Cabana constituye una localidad representativa de dichos paisajes, pues, análogamente a otros pueblos andinos del Perú, debido a la diversificación de sus actividades económicas (comercio, industria, turismo, etc) (Sánchez, 2017) y a la expansión de la frontera agrícola sobre tierras frágiles, con el uso de métodos contraproducentes (Alwang et al., 2013), corre el riesgo de perder importantes espacios con gran valor socioeconómico y ecológico para el futuro.

Actualmente, la teledetección y los SIG facilitan los análisis multitemporales, a través de imágenes satelitales y permiten detectar eficientemente cambios en las 
coberturas vegetales y en el uso del territorio (Álvarez y Agredo, 2013; Palacios, 2015), evidenciando, de manera fidedigna, problemas de reducción, degradación y reemplazo de áreas de vegetación natural, así como cambios del uso del suelo por ocupación agrícola, ganadera y urbana (Aly et al., 2016; Ruiz et al., 2013), además de problemas asociados a la deforestación e impactos ambientales de diversa índole (Florez-Yépez et al., 2017). Proporciona información pertinente para establecer lineamientos de gestión de recursos naturales y para la elaboración de planes de ordenamiento territorial (Ramírez-García et al., 2016; Trucíos-Caciano et al., 2011).

El objetivo fue determinar los cambios en las coberturas de las asociaciones vegetales y en las formas de uso del territorio a través del tiem-
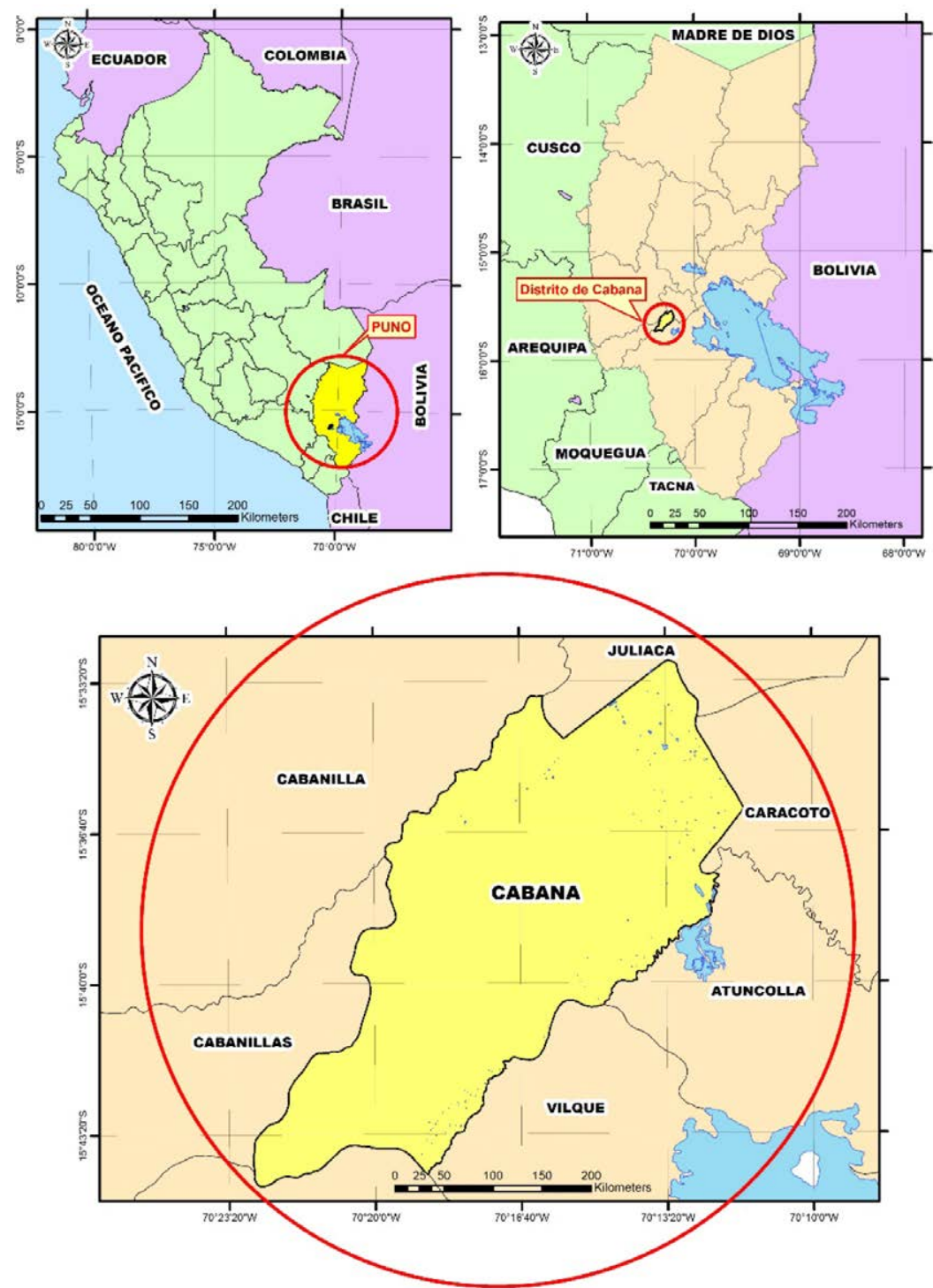

Figura 1. Localización del distrito de Cabana. Nota: fuente propia de la investigación. po, mediante el análisis de imágenes satelitales Landsat en la época de avenida en el distrito de Cabana durante el período 2000 al 2016.

\section{METODOLOGÍA}

\section{Ámbito de estudio}

El distrito de Cabana se ubica al sur este del territorio peruano, en la provincia

de San Román, región Puno, entre los 3825 a $4350 \mathrm{msnm}$ y coordenadas representativas de 15³8'58.08' S y 70¹9'18.67" O (Figura 1). Abarca un área de 193,16 km², en la ecorregión de puna húmeda (Britto, 2017), incluye altiplanicies y zonas colinosas con una fisiografía de pajonal altoandino donde predominan los géneros Festuca, Stipa y Calamagrostis, plantas cespitosas y arbustivas de porte bajo (MINAM, 2015). 
Presenta un rango de temperatura media anual de 7 a $10{ }^{\circ} \mathrm{C}$, que puede llegar a $-10{ }^{\circ} \mathrm{C}$ en junio, humedad relativa entre 53 a $59 \%$ y precipitaciones anuales de 629 a $755 \mathrm{~mm}$ (SENAMHI, 2018). Las principales fuentes de agua provienen de acequias, lagunas estacionales y el pequeño río Cabana, cuyo flujo solo se percibe en la actualidad durante la época de lluvias.

Al 2007 tuvo una población de 4392 habitantes y para el 2017 (último censo) llegó a 5215 (INEI, 2011; INEI, 2018), distribuida en pequeñas localidades y caseríos, cuya actividad principal es la agricultura de secano llevada a cabo entre setiembre y abril (época lluviosa), con los cultivos de papa, haba, cañihua y más extensamente quinua, cultivada ahora con fines de exportación mediante asociaciones productivas. La alfalfa es una forrajera que se cultiva todo el año, mediante dos canales de irrigación (Lupaca, 2018), para la crianza de ganado vacuno, además se complementa con ganado ovino y camélido en menor proporción. El comercio es otra actividad que actualmente en el área urbana viene tomando relevancia.

\section{Determinación de cambios multi- temporales de la vegetación y uso del suelo}

Preprocesamiento digital de las imágenes satelitales. Se obtuvieron imágenes satelitales Landsat desde la plataforma virtual www.earthexplorer.usgs.gov (USGS, 2018), de fechas 13 de abril del 2000, 25 de abril del 2005, 25 de abril del 2010 y 24 de marzo del 2016, meses en que finaliza la temporada lluviosa y presentan escasa cobertura nubosa, además de que, en estos momentos, la vegetación alcanza su máximo desarrollo. La información fue geocodificada con proyección UTM, esferoide y datum WGS 84, Zona 19 Sur y una resolución espacial de 30 metros. Se realizaron las correcciones geométricas, reasignando valores espectrales mediante el método del vecino más cercano para minimizar el cambio de la resolución de los píxeles, luego se hicieron correcciones radiométricas a través de la modificación de niveles digitales.

El área de estudio se delimitó con la imagen satelital Landsat 8 mediante ArcGis v10.5, utilizando el mapa base obtenido del proyecto: "Implementación de Procesos de Ordenamiento Territorial "IPOT" de la Gerencia Regional de Recursos Naturales y Gestión de Medio Ambiente del Gobierno Regional Puno". Se consideró una clasificación supervisada, para lo cual se identificaron y georreferenciaron 150 puntos de muestreo de vegetación en toda el área del distrito (GPS Garmin Etrex 30), en busca de representatividad de las asociaciones vegetales identificadas en las imágenes satelitales, mediante fotointerpretación visual basada en la combinación de bandas de color falso 3-5-2.

Clasificación supervisada, cambios de vegetación y uso de suelos. Una vez reconocidas las asociaciones vegetales in situ mediante el análisis de cuadrantes aleatorios, el procesamiento de imágenes satelitales Landsat se realizó utilizando el software ENVI v5.1, se aplicó la corrección radiométrica y atmosférica con el método FLAASH (Fast Line-of-sight Atmospheric Analisys Spectral Hypercubes), posteriormente se procedió a realizar un Layer estaquin para obtener una imagen satelital compuesta de 6 bandas blue, green, red, NIR, SWIR 1 y SWIR2. Para la discriminación visual se utilizó la composición de 6-4-2, se agregaron los puntos de muestreo de la vegetación para la clasificación supervisada por el método de máxima verosimilitud, para cada una de las imágenes de los años 
2000 al 2016, y se obtuvieron, con ello, los mapas de asociaciones vegetales y uso de suelos por cada año. El análisis comparativo entre mapas se realizó a través de la cuantificación de los pixeles que se mantuvieron o cambiaron, seguidamente se calcularon las áreas de cada asociación vegetal y cambio de uso de suelo, para detectar ganancias o pérdidas en hectáreas.

\section{Herborización e identificación de asociaciones vegetales}

Se realizaron herborizaciones que incluyeron trabajos de recolección, prensado, secado y montaje de las muestras de flora obtenidas por cada uno de los 150 puntos de muestreo según procedimientos de la BCMF (1996), para su posterior identificación de las especies mediante el uso de claves dicotómicas y descriptivas para flora de los Andes (Pestalozzi y Torrez, 1998; Salvador, 2002; Tovar y Oscanoa, 2002).

La vegetación se muestreó desde cuadrantes aleatorios de $1 \mathrm{~m}^{2}$ (Mostacedo y Fredericksen, 2000), con los que se determinó la cobertura vegetal del área dividiendo el cuadrante en 16 subcuadros iguales, donde cada uno representa el 6,25\% de la superficie del cuadrante (Soto, 2015). El porcentaje de cobertura se calculó mediante la siguiente expresión: Cobertura $(\%)=\sum\left(X_{\mathrm{I}} *\right.$ $6,25 \%$ ). Donde: $X_{\mathrm{I}}=$ número de subcuadros que aparece en una determinada especie en el cuadrante (Soto, 2015). Luego la cobertura total representó la suma de porcentajes de cada especie y la nominación científica de la (o las) especie con mayor porcentaje definió el nombre de la asociación vegetal.

Se consideró como asociación vegetal una comunidad conformada por una o varias especies características, con fisionomía uniforme y distribución propia de un hábitat particular (Molina, 2001; Smith y Smith,
2001). La nomenclatura de las asociaciones vegetales y su tipología sintaxonómica se fundamentó en el Código Internacional de Nomenclatura Fitosociológica (Alcaraz, 2013; Weber et al., 2000), determinando solo el sintaxón Asociación. Para esto, se agregó al género de la especie dominante (en cobertura y frecuencia) el sufijo etum, manteniendo el epíteto específico en genitivo cuando su cobertura fue mayor a 75 $\%$. Si dos especies en adición alcanzaron o superaron el $50 \%$ de cobertura del área evaluada, se tomaron ambos géneros con el respectivo sufijo para dar nombre a la asociación; además, para el registro florístico vegetacional solo se tomaron en cuenta las especies que alcanzaron más del 0,25\% de cobertura en los cuadrantes.

\section{Análisis estadístico}

Se aplicaron estadísticas descriptivas de las áreas por tipo de vegetación y uso de suelo en hectáreas y en porcentajes. También se determinó la tasa de cambio de acuerdo con la siguiente fórmula (Escandon et al., 2018; Palacio-Prieto et al., 2004):

$$
T d=\left\{\left[\left(\frac{S 2}{S 1}\right)^{\frac{1}{n}}\right]-1\right\} * 100
$$

Donde: $T d=$ Tasa de cambio anual en porcentaje, $S 2=$ área del año final, $S 1=$ área del primer año, $n=$ años del período de análisis. Para evaluar el grado de concordancia y exactitud total de la clasificación por año se utilizó el índice de Kappa $(K)$, cuya fuerza de concordancia se mide en la escala: 0 concordancia pobre; $0,01-0,2$ leve; 0,21 - 0,40 media; 0,41 - 0,60 moderada; 0,61 - 0,80 considerable y $0,81-1$ casi perfecta (Abraira, 2001; dos Santos y Santos, 2007). Para analizar y cuantificar los cambios y 
transferencias de una forma de cobertura a otra se elaboraron matrices de transición entre años, además se realizaron comparaciones " $t$ " de Student entre vegetación natural y cultivada de los años 2000 y 2016 desde los porcentajes de cobertura, asumiendo varianzas desiguales. Los procedimientos estadísticos se ejecutaron con el Programa SPSS v22.

\section{Resultados y discusión}

\section{Asociaciones vegetales}

Se identificaron seis asociaciones vegetales en la jurisdicción del distrito de Cabana, con una composición florística y características del hábitat relativamente diferentes entre ellas (Tabla 1). La asociación con mayor diversidad fue Jaravetum ichuae con 15 especies y luego Calamagrostio vicunaro - Festucetum dolichophyllae con 14; la más pobre fue Festucetum orthophyllae con solo tres especies; en todo el ámbito estudiado se registraton 34 especies distintivas, lo cual se considera como baja diversidad comparada con otros estudios florísticos en el altiplano (Arteta et al., 2006; Condori-Castillo, 2012; Montesinos-Tubée et al., 2015); aunque, en este caso, el estudio no estuvo orientado a caracterizar riqueza florística, pero la prevalencia de las especies principales fue similar a las que reportan dichos autores (Jarava ichu, Festuca

Tabla 1. Asociaciones vegetales naturales identificadas en el distrito de Cabana

\begin{tabular}{|c|c|c|c|c|c|c|}
\hline $\mathbf{N}^{\circ}$ & $\begin{array}{c}\text { Asociación } \\
\text { vegetal }\end{array}$ & $\begin{array}{c}\text { Área } \\
\text { distrito } \\
2016(\%)\end{array}$ & $\begin{array}{c}\text { Especies } \\
\text { predominantes }\end{array}$ & $\begin{array}{l}\text { Cob. } \\
(\%)\end{array}$ & $\begin{array}{c}\text { Otras especies } \\
\text { asociadas }\end{array}$ & Hábitat \\
\hline 01 & $\begin{array}{l}\text { Festucetum } \\
\text { orthophyllae }\end{array}$ & 8,77 & $\begin{array}{l}\text { Festuca } \\
\text { orthophylla }\end{array}$ & 70 & $\begin{array}{l}3 \text { especies. } \\
\text { Jarava ichu } \\
\text { Stipa obtusa }\end{array}$ & $\begin{array}{l}\text { Pajonal agreste, entre } 3 \\
850 \text { y } 3900 \text { msnm, suelo } \\
\text { arenoso, casi desértico. }\end{array}$ \\
\hline 02 & Jaravetum ichuae & 27,16 & Jarava ichu & 75 & $\begin{array}{l}15 \text { especies. } \\
\text { Aristida enodis. } \\
\text { Muhlenbergia peruviana } \\
\text { Festuca dolichophylla } \\
\text { Lepechinia meyenii } \\
\text { Tetraglochin cristatum } \\
\text { Baccharis tricuneata, etc }\end{array}$ & $\begin{array}{l}\text { Entre } 3900 \text { y } 4 \\
350 \text { msnm, pajonal } \\
\text { altoandino, de pampa y } \\
\text { zonas pedregosas, suelo } \\
\text { más orgánico. }\end{array}$ \\
\hline 03 & $\begin{array}{l}\text { Calamagrostio } \\
\text { vicugnaro - } \\
\text { Festucetum } \\
\text { dolichophyllae }\end{array}$ & 47,36 & $\begin{array}{l}\text { Festuca } \\
\text { dolichophylla } \\
\text { Calamagrostis } \\
\text { vicunarum }\end{array}$ & 30 & $\begin{array}{l}14 \text { especies. } \\
\text { Muhlenbergia fastigiata } \\
\text { Alchemilla pinnata } \\
\text { Tagetes pusilla } \\
\text { Trifolium amabile, etc }\end{array}$ & $\begin{array}{l}\text { Entre } 3850 \text { y } 3950 \\
\text { msnm, suelos ligeramente } \\
\text { húmedos a secos, de buen } \\
\text { drenaje. }\end{array}$ \\
\hline 04 & $\begin{array}{l}\text { Adesmetum } \\
\text { spinosissimae }\end{array}$ & 2,78 & $\begin{array}{l}\text { Adesmia } \\
\text { spinosissima }\end{array}$ & 80 & $\begin{array}{l}7 \text { especies. } \\
\text { Baccharis tricuneata } \\
\text { Tetraglochin cristatum } \\
\text { Grindelia boliviana, etc }\end{array}$ & $\begin{array}{l}\text { Matorral arbustivo de } \\
\text { porte bajo, entre } 3900 \\
\text { a } 4000 \mathrm{msnm} \text {, laderas } \\
\text { pedregosas }\end{array}$ \\
\hline 05 & $\begin{array}{l}\text { Muhlenbergetum } \\
\text { fastigiatae }\end{array}$ & 13,39 & $\begin{array}{l}\text { Muhlenbergia } \\
\text { fastigiata }\end{array}$ & 90 & $\begin{array}{l}4 \text { especies. } \\
\text { M. ligularis } \\
\text { C. vicunarum } \\
\text { Festuca dolichophylla }\end{array}$ & $\begin{array}{l}\text { Entre } 3825 \text { a } 3900 \\
\text { msnm, pradera de porte } \\
\text { bajo, cespitoso, suelos de } \\
\text { relativamente húmedos a } \\
\text { hidromórficos }\end{array}$ \\
\hline 06 & $\begin{array}{l}\text { Jaravo ichu- } \\
\text { Tetraglochetum } \\
\text { cristatae }\end{array}$ & 0,60 & $\begin{array}{l}\text { Jarava ichu } \\
\text { Tetraglochin } \\
\text { cristatum }\end{array}$ & $\begin{array}{l}50 \\
40\end{array}$ & $\begin{array}{l}4 \text { especies. } \\
\text { Cumulupuntia boliviana } \\
\text { Echinopsis pentlandii }\end{array}$ & $\begin{array}{l}\text { Pajonal arbustivo, suelos } \\
\text { pobres y secos, laderas y } \\
\text { cumbres, entre } 3900 \text { a } 3 \\
950 \mathrm{msnm} \text {. }\end{array}$ \\
\hline
\end{tabular}

Nota. Fuente propia de la investigación. 
dolichophylla, F. orthophylla, T. cristatum, Muhlenbergia y otras como Adesmia, Bromus, Grindelia, etc.).

Estudios específicos sobre asociaciones vegetales en la región, son escasos. Resalta el de Galán de Mera et al. (2003), quienes realizaron evaluaciones al sur de la región Puno (Mazocruz), y describieron también las asociaciones Calamagrostietum como graminales de zonas húmedas $\mathrm{y}$ Festucetum orthophyllae como pajonales de altura. Otras asociaciones equivalentes a las de Cabana, descritas en otras regiones andinas, podrían considerar a Calamagrostio tarmensis - Hypericetum laricifolii identificada en el páramo de Cajamarca (Galán de Mera et al., 2015) y Diplostephio tovari - Festucetum orthphyllae de los Andes del sur Perú (Galán de Mera et al., 2003). En los altos Andes del centro del Perú también las especies que conforman las formaciones vegetales más importantes son $F$. dolichophylla y Calamagrostis (Yaranga et al., 2018).

\section{Cambios interanuales de las asocia- ciones vegetales}

La vegetación natural total disminuyó notablemente en cinco años, en el 2000 la cobertura superaba 12500 ha y para el 2005 llegó a 10178 ha, y se mantuvo en similar cobertura hasta el 2016 (Figura 2 y Tabla 2). Según asociaciones vegetales, la mayor pérdida la tuvo Muhlenbergetum fastigiatae, donde en el año 2000 ocupaba el 43,96 \% de la vegetación natural y para al año 2016 solo alcanzó el 13,39 \% de la superficie del distrito, esto es, solamente la tercera parte de su área original. Estas áreas fueron reemplazadas por cultivos anuales (1 $131 \mathrm{ha}$ ) y por campos para forrajeras cultivadas (235,7 ha), debido a los suelos más húmedos y a que están por debajo de los $3900 \mathrm{msnm}$. Sin embargo, su mayor área fue reemplazada por la asociación Calamagrostio vicunaro - Festucetum dolicophyllae (2 026,2 ha), cuyas áreas en el año 2000 ocupaban el 20,39\%, hasta llegar a cubrir el 47,31 \% de la vegetación natural para el año 2016 (Tabla 3, Figura 2). Así, esta sucesión, probablemente inducida por el sobrepastoreo, quema, uso agrícola, entre otros, generó un hábitat diferente y con nuevas características ecológicas, con condiciones más agrestes por el predominio de pajonales altamente lignificados como Calamagrostis y Festuca (Salvador, 2002), propios de suelos menos productivos y más secos (Matteucci, 2012).

El área de asociaciones que incluye matorrales y vegetación arbustiva también decreció. Jaravo ichu - Tetraglochetum cristatae, en el 2000 abarcó $0,71 \%$ del área y para el 2016 descendió a 0,60 \%; similarmente Adesmetum spinosissimae del 4,02 \% que cubría en el 2000, para el año 2016 solo quedó el 2,78 \%. Llama la atención que en el distrito de Cabana no se evidenció ningún tipo de asociación arbustiva (solo árboles aislados), pero se tienen reportes que previo al año 2000 eran habituales los rodales nativos de Polylepis (Yallico, 1992), otro indicio que también advierte la degradación de la vegetación natural en el lugar. Condori-Castillo (2012) explica que el cambio de uso de suelo por causas antropogénicas induce la fragmentación del hábitat, al conducir a menor riqueza florística y una menor cobertura de la vegetación nativa, e incluso al generar suelo desnudo o degradado, como lo presenta también la localidad de Cabana.

\section{Cambios en el uso del suelo}

Además de los seis tipos de asociaciones vegetales, se identificaron otras ocho clases de cobertura y de uso de suelo para el año 2000, nueve para el 2005 y diez para el 


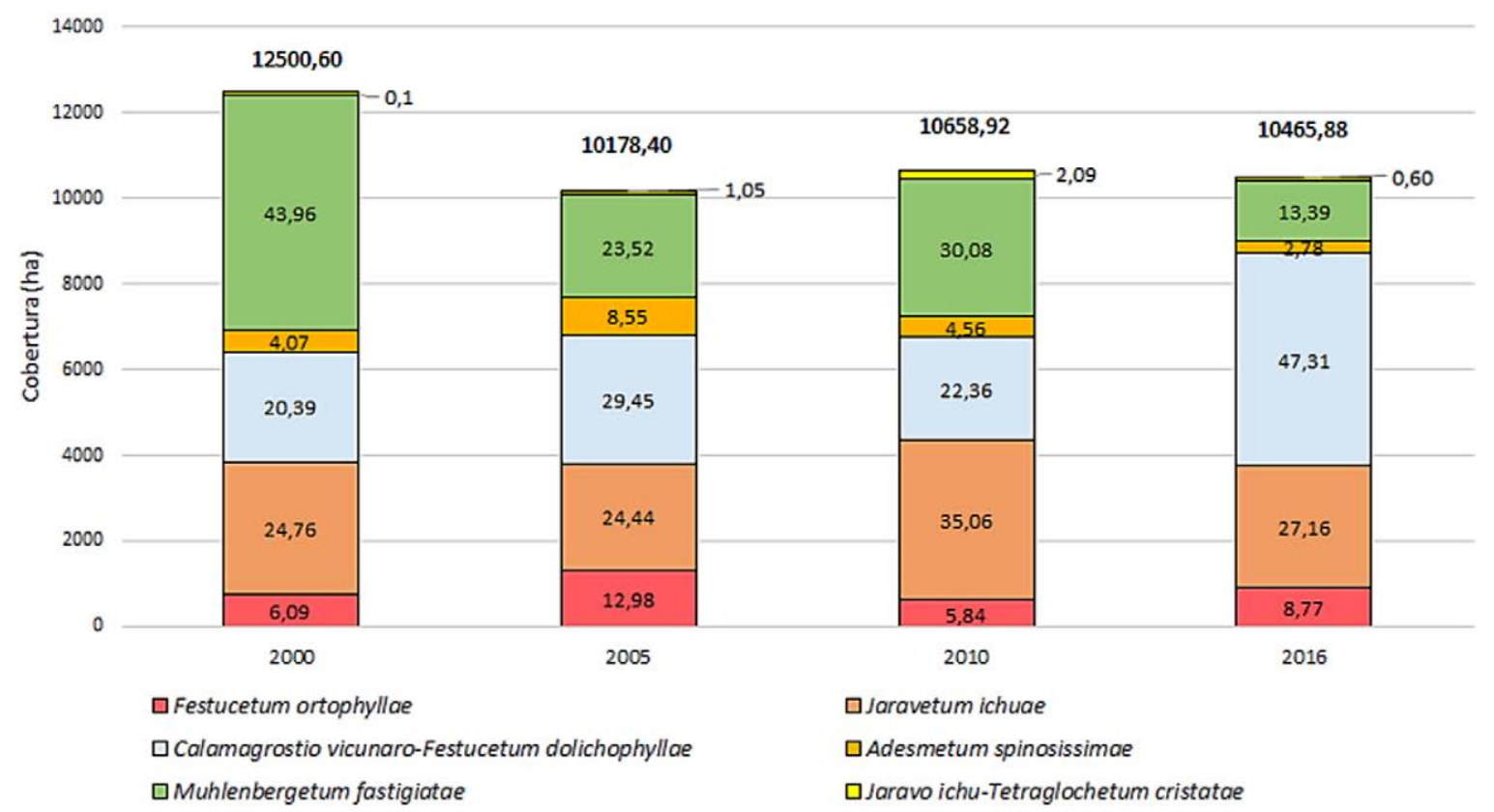

Figura 2. Cambios en la cobertura de las asociaciones vegetales naturales en el distrito de Cabana, años 2000 al 2016. Los números al interior de cada barra representan cobertura en porcentajes y en el extremo superior externo, el área total de la vegetación en hectáreas. Nota: Fuente propia de la investigación.

Tabla 2. Cambios multitemporales en la cobertura de la vegetación y usos de suelo (ha) en el distrito de Cabana desde el año 2000 al 2016.

\begin{tabular}{lcccccc}
\hline \multicolumn{1}{c}{ Vegetación y uso del suelo } & $\mathbf{2 0 0 0}$ & $\mathbf{2 0 0 5}$ & $\mathbf{2 0 1 0}$ & $\mathbf{2 0 1 6}$ & $\begin{array}{c}\text { Incremento } \\
\mathbf{2 0 0 0}-\mathbf{2 0 1 6} \\
\text { (\%) }\end{array}$ & $\begin{array}{c}\text { tasa de cambio } \\
\text { anual (\%) }\end{array}$ \\
\hline Festucetum orthophyllae & & & & & 20,5 & 4,7 \\
Jaravetum ichuae & 761,8 & 1321,3 & 622,6 & 918,1 & $-8,2$ & $-2,1$ \\
Calamagrostio $v$. Festucetum $d$. & 2549,4 & 2997,6 & 2383,7 & 4950,9 & 94,2 & 18,1 \\
Adesmetum spinosissimae & 5093,4 & 2487,9 & 3737,1 & 2842,2 & $-42,9$ & $-13,1$ \\
Muhlenbergetum fastigiatae & 5495,4 & 870,1 & 486,2 & 290,5 & $-74,5$ & $-28,9$ \\
Jaravo i. - Tetraglochetum c. & 89,2 & 107,1 & 222,7 & 62,6 & $-29,8$ & $-8,5$ \\
TOTAL vegetación natural & 12499,0 & 10178,4 & 10658,9 & 10465,8 & $-16,3$ & $-4,3$ \\
Cultivos anuales & 4384,5 & 5680,9 & 4851,3 & 6215,6 & 41,7 & 9,1 \\
Cultivos perennes forrajeros & 748,7 & 1009,0 & 1553,8 & 899,4 & 20,1 & 4,7 \\
TOTAL vegetación cultivada & 5133,2 & 6689,9 & 6405,1 & 7114,9 & 38,6 & 8,5 \\
Área urbana & 1,5 & 73,8 & 31,2 & 236,9 & 15700,0 & 40.7 \\
Área salinizada - degradada & 34,6 & 40,3 & 92,6 & 120,1 & 247,5 & 36,5 \\
Terreno con escasa vegetación & 806,2 & 1771,4 & 1146,7 & 713,3 & $-11,5$ & $-3,0$ \\
Pajonal quemado & 0 & 0 & 61,7 & 35,4 & $>100$ & $>100$ \\
Roquedal & 479,6 & 410,7 & 543,5 & 419,2 & $-12,6$ & $-3,3$ \\
Río & 50,7 & 49,4 & 36,9 & 76,0 & 49,8 & 10,6 \\
Laguna & 178,9 & 17,8 & 222,8 & 29,7 & $-83,4$ & $-36,2$ \\
Banco de arena & 132,0 & 83,9 & 116,2 & 104,3 & $-20,9$ & $-5,7$ \\
TOTAL & 19315,7 & 19315,7 & 19315,7 & 19315,7 & &
\end{tabular}

Nota: fuente propia de la investigación 


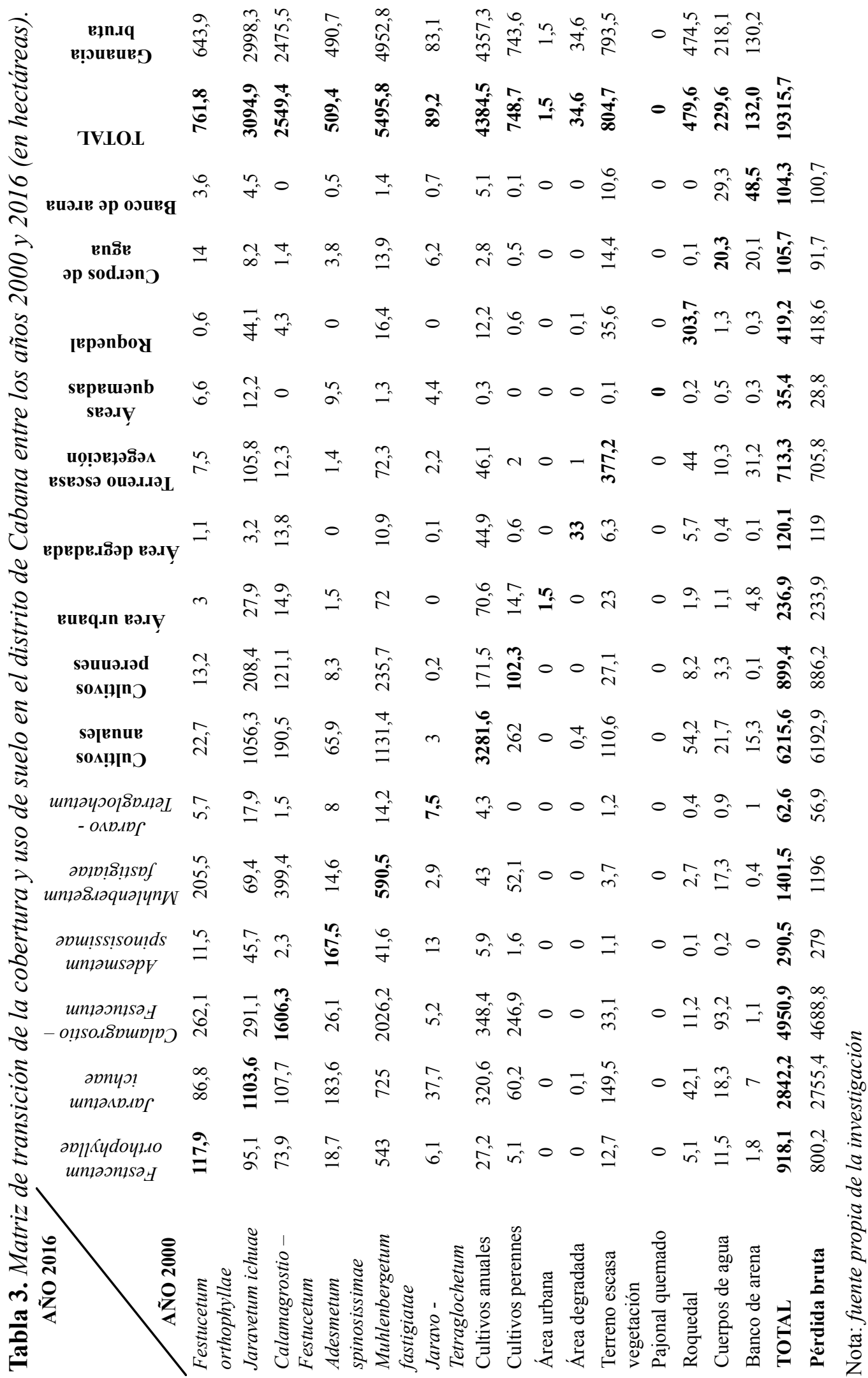


2010 y 2016 (Tabla 2); es decir, aumentaron las formas de uso del suelo en el tiempo. Estas diferencias se ilustran con la Figura 3, donde las superficies con mayor magnitud de cambio se dieron en la vegetación natural que, del $65 \%$ del área del distrito llegó a 54 $\%$ en 2016, luego el área cultivada que del $27 \%$ subió al $37 \%$ del área distrital; además, los espejos de agua del $2 \%$ disminuyeron a un $1 \%$ de la superficie en el 2016, y se hicieron más evidentes también, para este año, las áreas urbanas, áreas salinizadas y quemadas. Las variaciones en superficie de los cambios y el reemplazo de formas de uso entre los años 2000 y 2016 se detallan en la Tabla 3.

En 16 años el territorio de Cabana y su cobertura han cambiado notablemente por las modificaciones en el uso del suelo (Tabla 2). El factor vegetacional fue el más afectado, globalmente se ha reducido en 12 $\%$ del territorio, que significa unas 2034,71 ha en cobertura con una tasa de cambio anual de $-4,34 \%$; la asociación Muhlenbergetum tuvo la mayor pérdida con una tasa de cambio de $-28,94 \%$ anual, mientras que la asociación Calamogrostio vicunaro - Festucetum dolichophyllae adquiere una tasa de $18,05 \%$ anual, casi duplica su cobertura en ese lapso. Esta alteración en la vegetación natural sería indicio de que los suelos pierden fertilidad (humedad, materia orgánica, nutrientes), propios del pastizal de Muhlenbergia que vienen disminuyendo, además que esta especie es propia de una vegetación primaria y de suelos preferentemente húmedos (Giraldo-Cañas, 2009; Peterson y Giraldo-Cañas, 2011), pero en su lugar hay un reemplazo por especies más xerofíticas como Calamagrostis y Festuca que prosperan en suelos más pobres y secos (Stancik, 2003; Tapia, 1971).

En cambio, las áreas de cultivo vienen incrementando con una tasa de 8,51\% anual, han aumentado 38,61\% en los 16 años (1 981,8 ha) (Tabla 2). Actualmente el cultivo predominante en el distrito de Cabana es la quinua (Chenopodium quinoa), cuya demanda y alza de precios internacional ha motivado una mayor producción (Lupaca, 2018); su área, aunada a la de otros cultivos anuales (papa, oca, izaño, habas), hicieron aumentar el área cultivada a una tasa de $9,12 \%$ anual (5 66,86 ha/año). También ha aumentado el área de forrajeras perennes (alfalfa), desde 748,66 ha hasta 899,38
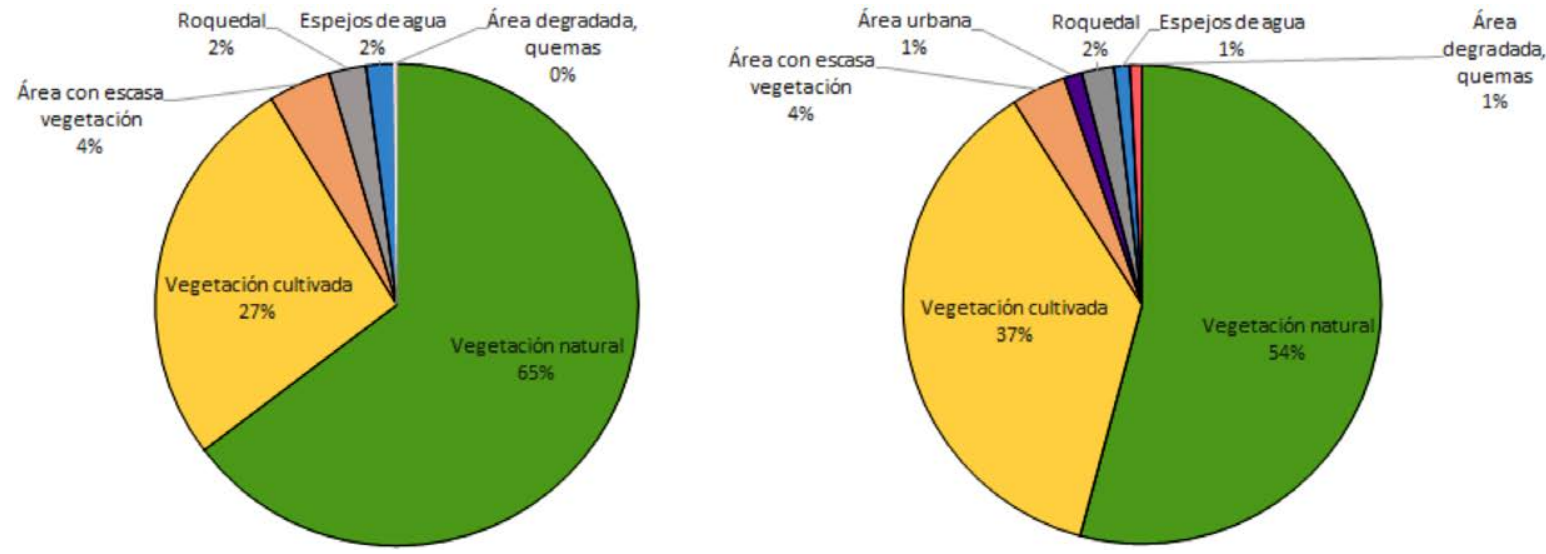

Figura 3. Cambios en la cobertura y uso del suelo en el distrito de Cabana, desde el año 2000 (arriba) y 2016 (abajo).

Nota: fuente propia de la investigación. 
ha en el 2016, a una tasa de 4,69\% anual; es decir, cada año se aumenta 42,18 ha de suelo para establecer forrajeras cultivadas. Las nuevas áreas utilizadas por la actividad agrícola reemplazaron, principalmente, coberturas de las asociaciones Calamogrostio vicunaro - Festucetum dolichophyllae, y ocupan 1131 ha por cultivos anuales y 235,7 ha por forrajeras perennes, luego de la asociación Jaravetum ichuae ocuparon 1 056,3 ha y 208,4 ha los cultivos anuales y perennes respectivamente (Tabla 3). Estos cambios de la vegetación natural y cultivada fueron estadísticamente significativos en el tiempo $(p<0,001)$, según se aprecia en la Figura 4.

El incremento de estas áreas cultivadas, sin duda se revierte en beneficios económicos a corto o mediano plazo; pero los fundamentos de la moderna agricultura sostenible exigen que el desarrollo agrario debe estar respaldado por una imparcial zonificación agroecológica que propicie un apropiado ordenamiento territorial, cuyos beneficios se extiendan a largo plazo (Ruiz et al., 2015; Suárez, 2014), condición que al parecer no se considera en el distrito de Cabana.

La disminución de vegetación natural y el crecimiento de áreas agrícolas es común a muchas latitudes. Yan et al. (2018) reportan que en el 2000 la vegetación natural en un hábitat de Mongolia representaba el $58,81 \%$ del área evaluada y para el año 2016 representaba el 48,14\% de la misma área, una reducción casi similar (10 $\%)$ a lo que ocurrió en Cabana (Figura 2). En Culiacán, México, el área agrícola en el 2000 abarcaba $2,87 \%$ del territorio y para el 2014 llegó a 8,16 \% (Sanhouse- García et al., 2017); en otros lugares este crecimiento

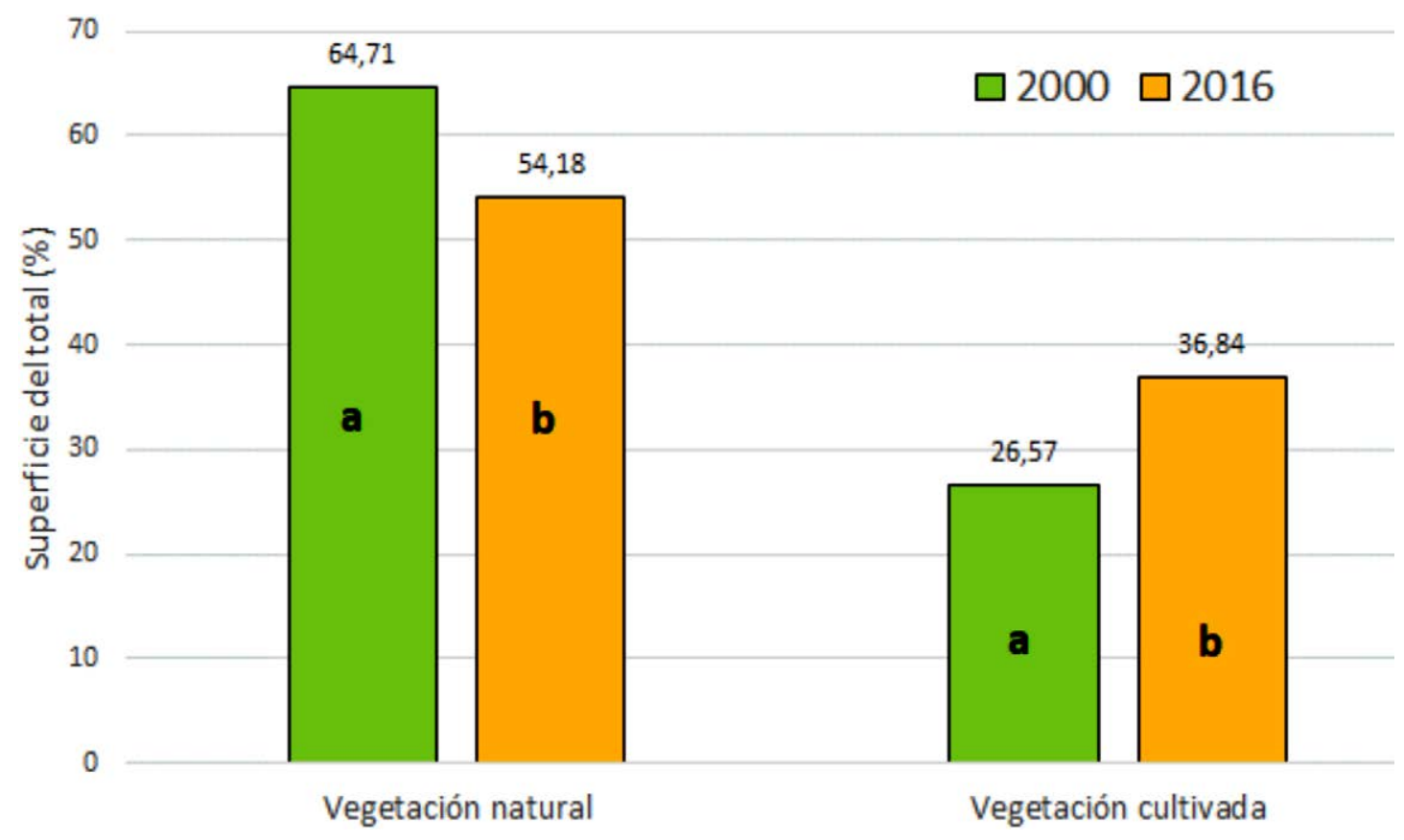

Figura 4. Cambios en la cobertura de la vegetación natural y cultivada entre los años 2000 y 2016 en el distrito de Cabana. Letras diferentes entre barras de un mismo tipo de vegetación indican diferencias significativas a la prueba de $t$.

Nota: Fuente propia de la investigación. 
es mínimo, como en una cuenca altiplánica de México, donde el área agrícola entre el 2000 y 2008 solo se incrementó en un 0.03 \% (García-Orozco et al., 2012) y en otros ámbitos, también suele haber una disminución del área agrícola impuesta mayormente por el incremento del área urbana (Liu et al., 2019; Nath et al., 2018; Roy e Inamdar, 2019). Las actividades que ganan terreno en la cobertura del suelo en Latinoamérica son, básicamente, la agricultura y la urbanización (Camacho-Sanabria et al., 2015; Escandon et al., 2018).

En efecto, otro cambio manifiesto en el uso de suelo en Cabana se evidenció en el surgimiento del área urbana. Para el año 2000 era imperceptible esta categoría y para el 2016 el área alcanzó las 237 has y el crecimiento continuaría a una tasa de 46,9\% anual (Tabla 2 y Figura 3), ganando espacios a partir de las asociaciones Muhlenbergetum, Jaravetum y también de áreas de cultivo (Tabla 3). Esto también ocurre en otros ámbitos, aunque en diferentes proporciones. Por ejemplo, en el municipio de León (Guanajuato, México) para 1970 no se reportó área urbana y para el 2007 (después de 36 años) está área ascendió a 80 ha, aumentando a un ritmo de 2,1 ha/año (Trucíos - Caciano et al., 2011); en Cabana, en solo 16 años creció tres veces esa ciudad, a un ritmo de 14,7 ha/año. En una localidad de China aumentó $0,67 \%$ en 22 años (Liping et al., 2018) y en otra de Turquía aumentó 135,72 \% el área en tres años (Erener et al., 2012). En general, las zonas urbanas se incrementan a costa de pastizales, zonas agrícolas y vegetación secundaria (Sotelo et al., 2015).

Se aprecia también un incremento importante de las áreas salinizadas y degradadas, a una tasa de 36,53\% anual, debido, probablemente, a frecuentes eventos de anegación de los terrenos y a eventuales proyectos de irrigación que se desarrollaron en Cabana (INTECSA, 1993; Lupaca, 2018), los cuales, además, propiciaron la degradación de la cubierta vegetal con una consecuente erosión hídrica y eólica, causales fundamentales de los procesos de desertificación que se vienen suscitando en todo el mundo (Granados-Sánchez et al., 2013).

Los humedales, representados por pequeñas lagunas temporales, en el año 2000 abarcaron 178,9 has, que se redujeron en un $83,39 \%$ para el 2016 (29,71 ha), y alcanzaron una tasa de cambio de $-36,16 \%$ anual. Ello implica pérdida de necesarias fuentes de agua para actividades humanas y para requerimientos del ecosistema y magnifican, peligrosamente, los efectos del cambio climático, que ya viene modificando la hidrología de los Andes, conducente a la escasez de recursos hídricos y a la desecación de los suelos (Vuille, 2013). Similar suceso ocurrió en Culiacán (México), donde la cobertura de humedales disminuyó un $65 \%$ en 24 años (Sanhouse-García et al., 2017).

Los índices de Kappa para las clasificaciones de los cuatro años presentaron valores entre 0,77 y 0,89 , lo que explica un grado de precisión considerable en las coberturas determinadas, lo cual indica que los mapas elaborados se asemejan de un modo importante a las condiciones reales (Tabla 2).

En la Figura 5 se distingue la amplitud que adquiere el área para uso agrícola al cabo de los 16 años. La vegetación natural se aprecia muy fragmentada y recortada para Muhlenbergetum, excepto Calamogrostio vicunaro - Festucetum dolichophyllae que también ha ocupado áreas de otras asociaciones naturales, resultado de una sucesión secundaria por el uso del suelo con fines agropecuarios, principalmente. Los nuevos tipos de uso del suelo (áreas urbana, salinizada, quemada), así como los terrenos 

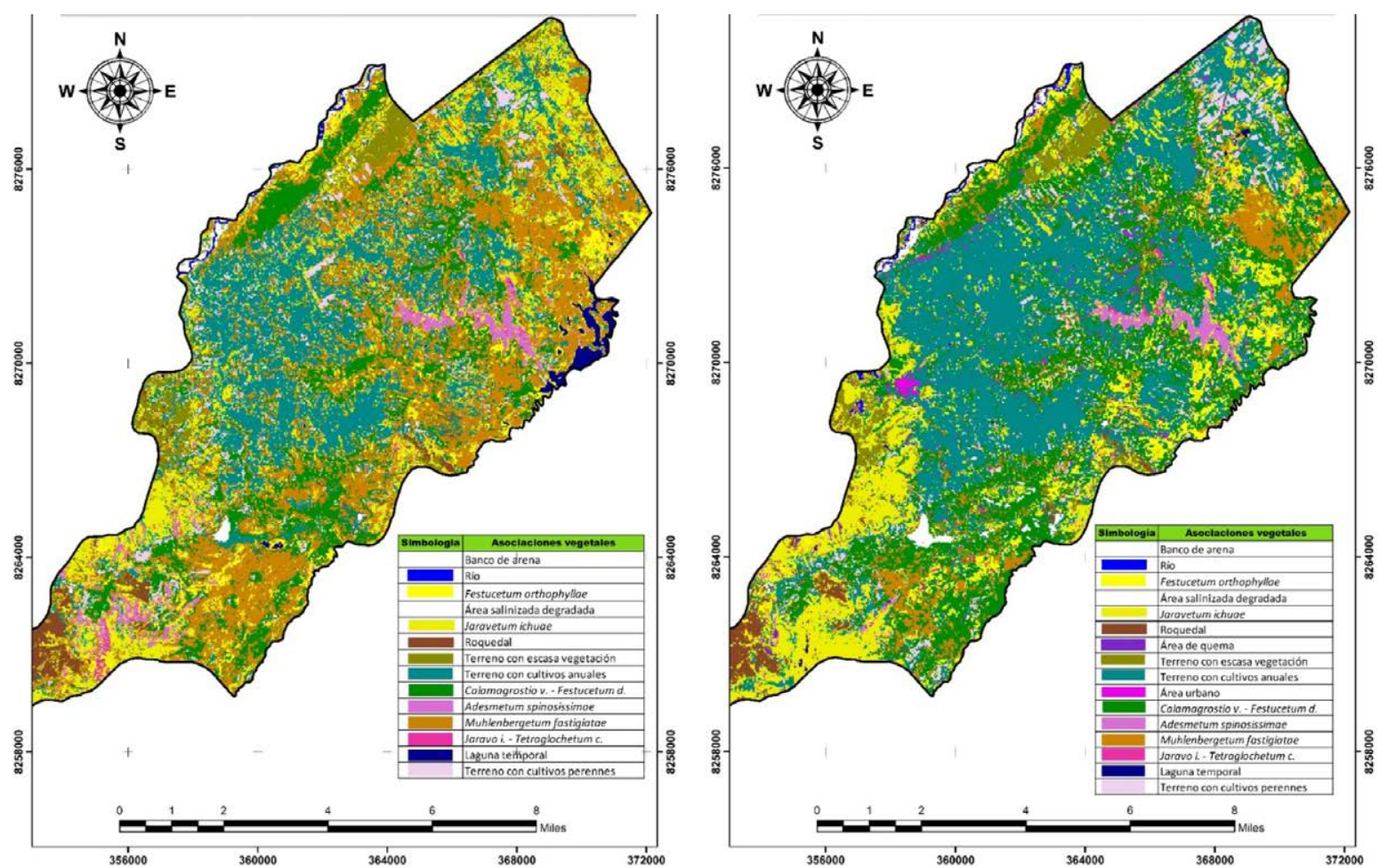

Figura 5. Cambio en el tiempo de la vegetación natural y uso del suelo en el distrito de Cabana desde el año 2000 (izquierda) y el 2016 (derecha).

Nota: Fuente propia de la investigación.

de escasa vegetación, se evidencian también en dicha figura y serían causales adicionales de procesos de degradación del ecosistema.

Finalmente, se considera que estos cambios de uso del suelo en el distrito de Cabana no fueron, fundamentalmente, por el incremento de la población humana, ya que para el año 2007 tenía 4843 habitantes y para el 2016 incrementó a solo 5215 habitantes (INEI, 2011; INEI, 2018). Ello permite deducir que más bien hubo un uso y ocupación más intensiva del territorio basada en la actividad agrícola, pues en el 2006 se cultivaba 0,84 ha/persona y para el 2016 cada persona cultivaba 2,34 ha (Lupaca, 2018) y esto podría continuar de manera progresiva hasta suprimir completamente el área de vegetación natural.

\section{Conclusiones}

Se determinaron seis tipos de asociaciones vegetales naturales en el distrito de Cabana, las que, en conjunto, desde el año 2000 al 2016 se han venido reduciendo en un $17 \%$ o prosperando asociaciones en reemplazo de vegetación primaria. El área agrícola incrementó un $38,6 \%$, y ocupó gran parte del área de la vegetación natural disminuida, lo cual, si bien repercutió en beneficios económicos, también estuvo asociado a la degradación de la vegetación natural con las consecuentes pérdidas de servicios ecosistémicos y con la incompatibilidad de una agricultura sostenible. Estos cambios, conjuntamente con el crecimiento del área urbana, áreas degradadas, quemadas y una disminución dramática de los humedales $(83 \%)$, podrían devenir en importantes 
riesgos ambientales a futuro, cuyos efectos pueden también intensificarse con la actual problemática ambiental global (fenómenos climáticos extremos, calentamiento global, contaminación), y comprometer el potencial de los recursos naturales y la calidad de vida de las personas.

Ante ello, surge la apremiante necesidad de modernizar la actividad agrícola y otros sistemas productivos, considerando modelos sostenibles en el tiempo, fundamentados en procesos de zonificación ecológica y ordenamiento territorial, previo al cambio de uso o manejo de los territorios, mucho más, si se considera la alta vulnerabilidad ecológica de los ecosistemas altoandinos, ante eventos ambientales extremos, y la necesidad permanente de recursos que demandarán las crecientes sociedades futuras. Los sistemas de información geográfica (SIG) constituyen la herramienta tecnológica elemental para ello y su acceso es actualmente universal. Otros estudios similares a este son necesarios para evidenciar lo que viene suscitándose en otros ámbitos de la región.

\section{RECONOCIMIENTOS}

Al Gobierno Regional Puno, Programa de Implementación de Procesos de Ordenamiento Territorial de la Gerencia de Recursos Naturales y Gestión de Medio Ambiente, por el apoyo logístico facilitado para el presente estudio.

\section{DECLARACIÓN DE LA CONTRIBUCIÓN DE LOS AUTORES}

El porcentaje total de contribución para la conceptualización, preparación y corrección de este artículo fue el siguiente: A.LD.C. $50 \%$, I.T.H. $50 \%$.

\section{DECLARACIÓN DE DISPONIBILIDAD DE LOS DATOS}

Los datos que respaldan los resultados de este estudio serán puestos a disposición por el autor correspondiente [A.L.D.C.], previa solicitud razonable.

\section{REFERENCIAS}

Abraira, V. (2001). El índice de Kappa. Semergen, 27(5), 247-249. https://doi.org/10.1016/ S1138-3593(01)73955-X

Alcaraz, F. (2013). Método fitosociológico. Universidad de Murcia, España. https://www.um.es/ docencia/geobotanica/ficheros/tema11.pdf

Álvarez, J. \& Agredo, G. (2013). Perdida de la cobertura vegetal y de oxígeno en la media montaña del trópico andino, caso cuenca urbana San Luis (Manizales). Luna Azul, 37, 30-48.

Alwang, J., Norton, G., Barrera, V. \& Botello, R. (2013). Conservation Agriculture in the Andean Highlands: Promise and Precautions. En S. Mann (Ed.), The Future of Mountain Agriculture. Springer Geography (pp. 21-38). Springer-Verlag. https://doi. org/10.1007/978-3-642-33584-6_3

Aly, A. A., Al-Omran, A., Sallam, A., Al-Wabell, M. \& Al-Shayaa, M. (2016). Vegetation cover change detection and assessment in arid environment using multi-temporal remote sensing images and ecosystem management approach. Solid Earth, 7, 713-725. https:// doi.org/10.5194/se-7-713-2016

Arteta, M., Corrales, M., Dávalos, C., Delgado, A., Sinca, F., Hernani, L. \& Bojórquez, J. (2006). Plantas vasculares de la bahía de Juli, lago Titicaca, Puno-Perú. Ecología Aplicada, 5(1,2), 29-36. https://doi.org/10.21704/rea. v5i1-2.314

BCMF - British Columbia Ministry of Forests. (1996). Techniques and procedures for collecting, preserving, processing, and storing botanical specimens. (Working Paper 18/1996). Ministry of Forests Research Program.

Britto, B. (2017). Actualización de las ecorregiones terrestres de Perú propuestas en el $L i$ bro Rojo de Plantas Endémicas del Perú. 
Gayana Botánica, 74(1), 15-29. http://dx.doi. org/10.4067/S0717-66432017005000318

Camacho-Sanabria, J. M., Pérez, J., Pineda-Jaimes, N. B., Cadena-Vargas, E. G., Bravo-Peña, L. C. \& Sánchez-López, M. (2015). Cambios de cobertura/uso del suelo en una porción de la Zona de Transición Mexicana de Montaña. Madera y Bosques, 21(1), 93-112. https://doi. org/10.21829/myb.2015.211435

CIFOR - Center for International Forestry Research. (2013). Bosques y agua: Lo que deberían saber los formuladores de políticas. (FactSheet $\mathrm{n} .^{\circ}$ 12). Programa de Investigación sobre Bosques, Árboles y Agroforestería - CGIAR. https://doi.org/10.17528/cifor/004175

Condori-Castillo, G. (2012). Influencia de la fragmentación en la diversidad de la flora silvestre y en los cambios de uso de suelo y cobertura vegetal en Huerta Huaraya, Puno. Ecosistemas, 21(1-2), 230-234.

Cotler, H., Sotelo, E., Domínguez, J., Zorrilla, M., Cortina, S. \& Quiñones, L. (2007). La conservación de suelos: Un asunto de interés público. Gaceta Ecológica, 83, 5-71.

Erener, A., Düzgün, S. \& Yalciner, A.C. (2012). Evaluating land use/cover change with temporal satellite data and information systems. Procedia Technology, 1, 385-389. https://doi.org/10.1016/j.protcy.2012.02.079

Escandón, J., Ordóñez, J. A., Nieto de Pascual, M. C., \& Ordóñez, M. J. (2018). Cambio en la cobertura vegetal y uso del suelo del 2000 al 2009 en Morelos, México. Revista Mexicana de Ciencias Forestales, 46(9), 27-53. https:// doi.org/10.29298/rmcf.v9i46.135

FAO - Food and Agriculture Organization. (2018). Guía de buenas prácticas para la gestión y uso sostenible de los suelos en áreas rurales. Alianza Mundial por el Suelo y FAO.

FAO -Food and Agriculture Organization. (2014). Cordillera de Los Andes, una oportunidad para la integración y desarrollo de América del Sur. Alianza para las Montañas.

Flórez-Yepes, G. Y., Rincón-Santamaría, A., Cardona P. S., \& Alzate-Alvarez, A. M. (2017). Análisis multitemporal de las coberturas vegetales en el área de influencia de las minas de oro ubicadas en la parte alta del sector de Maltería en Manizales, Colombia. DYNA, 84(201), 95-101. https://doi.org/10.15446/ dyna.v84n201.55759
Foley, J. A., Defries, R., Asner, G., Barford, C., Bonan, G., Carpenter, S. R., Chapin, S., Coe, M., Daily, G., Gibbs, H., Helkowski, J. H., Holloway, T., Howard, E. A., Kucharik, C., Monfreda, Ch., Patz, J., Prentice, C., Ramankutty, N., \& Snyder. P. K. (2005). Global Consequences of Land Use. Science, 309(5534), 570-574. https://doi.org/10.1126/ science. 1111772

Galán de Mera, A., Sánchez, I., Montoya, J., Linares, E., Campos, J., \& Vicente, J. A. (2015). La vegetación del norte del Perú: De los bosques a la jalca en Cajamarca. Acta Botánica Malaciana, 40, 157-190. https://doi.org/10.24310/ abm.v40i0.2505

Galán de Mera, A., Cáceres, C., \& González, A. (2003). La vegetación de la alta montaña andina del sur del Perú. Acta Botánica Malacitana, 28, 121-147. https://doi.org/10.24310/ abm.v28i0.7271

García-Orozco, J. A., Cedillo-Gutiérrez, J. G., Juan-Pérez, J. I., \& Balderas, M. A. (2012). Procesos de cambio en el uso del suelo de una microcuenca en el altiplano mexicano, el caso del río San José en el Estado de México. Papeles de Geografia, 56, 63-73.

Gil-Leguizarron, P., \& Morales-Puentes, M. (2016). Información espacial, herramientas de análisis en la transformación de las coberturas vegetales. Ingeniería e Innovación, 4(2), 15-22.

Giraldo-Cañas, D., \& Peterson, P. (2009). El género Muhlenbergia (Poaceae: Chloridoideae: Cynodonteae: Muhlenbergiinae) en Colombia. Caldasia, 31(2), 269-302.

Granados-Sánchez, D., Hernández-García, M. A., Vázquez-Alarcón, A., \& Ruíz-Puga, P. (2013). Los procesos de desertificación y las regiones áridas. Revista Chapingo Serie Ciencias Forestales y del Ambiente, 19(1), 45-66. https://doi.org/10.5154/r.rchscfa

Hamilton, L. S., Dudley, N., Greminger, G., Hassan, N., Lamb, D., Stolton, S., \& Tognetti, S. (2009). Los bosques y el agua. Estudio FAO - Montes 155.

Hansen, M. C., Potapov, P. V., Moore, R., Hancher, M., Turubanova, S. A., Tyukavina, A., Thau, D., Stehman, S. V., Goetz, S. J., Loveland, T. R., Kommareddy, A., Egorov, A., Chini, L., Justice, C. O., \& Townshend, J. R. (2013). High-Resolution Global Maps of 21st-Century Forest Cover Change. Science, 342, 850-853. https://doi.org/10.1126/science.1244693 
INEI - Instituto Nacional de Estadística e Informática. (2018). Perú: Crecimiento y distribución de la población total, 2017. Censos Nacionales 2017.

INEI - Instituto Nacional de Estadística e Informática. (2011). Puno, compendio estadistico. Oficina Departamental de estadística e Informática.

INTECSA - Internacional de Ingeniería y Estudios Técnicos S. A. (1993). Proyectos de riego y necesidades de agua en el sistema T.D.P.S. (Convenios ALA/86/03 y ALA/87/23). Repúblicas de Perú y Bolivia: Comisión de las Comunidades Europeas, Plan Director Global Binacional de Protección - Prevención de Inundaciones y Aprovechamiento de los Recursos del Lago Titicaca, Rio Desaguadero, Lago Poopo y Lago Salar de Coipasa (Sistema T.D.P.S.).

Liping, C., Yujun, S., \& Saeed, S. (2018). Monitoring and predicting land use and land cover changes using remote sensing and GIS techniques, case study of a hilly area, Jiangle, China. PLoS ONE, 13(7), e0200493. https:// doi.org/10.1371/journal.pone.0200493

Liu, F., Qin, T., Girma, A., Wang, H., Weng, B., Yu, Z. \& Wang, Z. (2019). Dynamics of landuse and vegetation change using NDVI and transfer matrix: A case study of the Huaihe River Basin. Polish Journal of Environmental Studies, 28(1), 213-223. https://doi. org/10.15244/pjoes/82900

Lupaca, N. K. (2018). El biocomercio de la quinua en el mercado global y sus efectos en los agricultores locales en Perú, estudio de caso: Cooperativa Agroindustrial Cabana (COOPAIN) Puno [Tesis Magister]. Pontificia Universidad Católica del Perú, Lima, Perú.

Matteucci, S. D. (2012). Ecorregión Puna. En J. Morello, S. Matteucci, A. Rodríguez, A. y M. Silva (Eds.). Ecorregiones y complejos ecosistémicos argentinos (pp. 87-127). Orientación Gráfica Editora SRL.

Matteuci, S. D., \& Colma, A. (1982). Metodología para el estudio de la vegetación. Secretaría General de la Organización de los Estados Americanos.

MINAM - Ministerio del Ambiente. (2015). Mapa nacional de cobertura vegetal. Dirección general de Evaluación, Valoración y Financiamiento del Patrimonio Natural.
Molina, L.A., Serna, E., \& Urrego, L. (2001). Clasificación fitosociológica de un bosque de niebla en la Reserva Natural Karagabi, Pueblo Rico, Risaralda. Crónica Forestal y del Medio Ambiente, 13(1), 1-17.

Molles, M. (2006). Ecología, conceptos y aplicaciones. Editorial MacGraw-Hill/Interamericana.

Montesinos-Tubée, D., Pinto, A., Beltrán, D., \& Galiano, W. (2015). Vegetación de un bosque de Polylepis incarum (Rosaceae) en el distrito de Lampa, Puno, Perú. Revista Peruana de Biología, 22(1), 087-096. https://doi. org/10.15381/rpb.v22i1.11125

Mostacedo, B., \& Fredericksen, T. (2000). Manual de métodos básicos de muestreo y análisis en ecología vegetal. Santa Cruz de la Sierra, Bolivia: Proyecto de Manejo Forestal Sostenible (BOLFOR).

Nath, B., Niu, Z. \& Singh, R. (2018). Land use and land cover changes, and environment and risk evaluation of Dujiangyan city (SW China) using remote sensing and GIS techniques. Sustainability, 10(4631), 1-32. https://doi. org/10.3390/su10124631

Palacio-Prieto, J. L., Sánchez-Salazar, M. T., Casado, J. M., Propin, E., Delgado, J., Velásquez, A, \& Márquez, R. (2004). Indicadores para la caracterización y ordenamiento del territorio. SEMARNAT-INE-UNAM.

Palacios, B. E. (2015). Análisis multitemporal de los cambios de la cobertura boscosa en la zona Pacifico Norte del departamento del Choco, 1990 - 2014 [Tesis Especialización]. Universidad de Manizales. Colombia.

Pestalozzi, M. U., \& Torrez, M. (1998). Flora ilustrada altoandina. M\&C, editores.

Peterson, P. M., \& Giraldo-Caña, D. (2011). Las especies de Muhlenbergia (Poaceae: Chloridoideae) de Argentina. Caldasia, 33(1), 21-54.

Ramírez-García, A. G., Cruz-León, A., Morales-Carrillo, N., \& Monterroso-Rivas, A. (2016). El ordenamiento ecológico territorial, instrumento de política ambiental para la planeación del desarrollo local. Estudios Sociales, 48(26), 69-99.

Ríos-Patrón, E., González-Mora, I. D., \& Cotler, H. (2015). Suelos, bases para su manejo y conservación. Secretaría de Medio Ambiente y Recursos Naturales - SEMARNAT y CECADESU. 
Roy, A. \& Inamdar, A. (2019). Multi-temporal Land Use Land Cover (LULC) change analysis of a dry semi-arid river basin in western India following a robust multi-sensor satellite image calibration strategy. Heliyon, 5, 1-20. https:// doi.org/10.1016/j.heliyon.2019.e01478

Ruiz, D. M., Martínez, J. P., \& Figueroa, A. (2015). Agricultura sostenible en ecosistemas de alta montaña. Biotecnología en el Sector Agropecuario y Agroindustrial, 13(1), 129-138. https://doi.org/10.18684/BSAA(13)129-138

Ruiz, V., Savé, R., \& Herrera, A. (2013). Análisis multitemporal del cambio de uso del suelo, en el Paisaje Terrestre Protegido Miraflor Moropotente Nicaragua, 1993 - 2011. Ecosistemas, 22(3), 117-123. https://doi.org/10.7818/ ECOS.2013.22-3.16

Salvador, M. L. (2002). Manual de pastos nativos del Parque Nacional Huascarán. Tarea Gráfica Educativa.

Sánchez, M. (2017). Comprender la agricultura en los Andes peruanos: Economía y política en la comunidad de Yanque (Caylloma, Arequipa). Revista Antropologías del Sur, 4(7), $235-256$.

Sanhouse-García, A. J., Bustos-Terrones, J., Rangel-Peraza, J. G., Quevedo-Castro, A., \& Pacheco, C. (2017). Multi-temporal analysis for land use and land cover changes in an agricultural region using open source tools. Remote Sensing Applications: Society and Environment, 8, 278-290. https://doi.org/10.1016/j. rsase.2016.11.002

Santos, M. A. dos, \& Santos, R. F. dos. (2007). Aplicación de índices de cambios para evaluación de las alteraciones en el uso de las tierras. Investigaciones Geográficas, (42), 163. http:// dx.doi.org/10.14198/INGEO2007.42.08

SENAMHI - Servicio Nacional de Meteorología e Hidrología. (2018). Información climática estación meteorológica Cabanillas. Ministerio de Ambiente. https://www.senamhi. gob.pe/main.php?dp=puno\&p=descarga-datos-hidrometeorologicos

Smith L., \& Smith, T. (2001). Ecología. Pearson Educación.

Song, X. P., Hansen, M., Stehman, S., Potapov, P. V., Tyukavina, A., Vermote, E. F., \& Townshend, J. R. (2018). Global land change from 1982 to 2016. Nature, 560, 639-643. https://doi. org/10.1038/s41586-018-0411-9
Sotelo-Caro, O., Chichia J., Sorani V., \& Flores, A. (2015). Cambios en la dinámica de deforestación de la subcuenca de un río en México: La imposibilidad de recuperación de los hábitats originales después del cese de la deforestación. Revista de Geografia Norte Grande, 61, 221-227. https://doi.org/10.4067/ S0718-34022015000200012

Soto S. F. (2015). Cálculo de la cobertura y densidad vegetal - Ecología. Ingeniería en Recursos Naturales Renovables, Universidad de Chile. http://franciscamsotosantander.blogspot.com/2015/11/calculo-de-la-cobertura-vegetal.html

Stancik, D. (2003). Las especies del género Festuca (Poaceae) en Colombia. Darwiniana, 41(14), 93-153. www.jstor.org/stable/23225112

Steffen, W., Richardson, K., Rockström, J., Cornell, S., Fetzer, I., Bennett, E., Biggs, R., Carpenter, S. R. de Vries, W., de Wit, C., Folke, C., Gerten, D., Heinke, J., Mace, G., Persson, L., Ramanathan, V., Reyers, B., \& Sörlin, S. (2015). Planetary boundaries: Guiding human development on a changing planet. Science, 347(6223), 1259855. https://doi.org/10.1126/ science. 1259855

Suárez, G. M. (2014). Apuntes sobre la zonificación agroecológica de los cultivos, particularidades en Cuba. Cultivos Tropicales, 35(4), 36-44.

Tapia, M. (1971). Pastos naturales del altiplano de Perú y Bolivia. Editorial Ecuador, IICA.

Tovar, O., \& Oscanoa, L. (2002). Guía para la identificación de pastos naturales alto andinos de mayor importancia ganadera. Instituto de Montaña.

Trucíos-Caciano, R., Estrada-Ávalos, J., Cerano-Paredes, J., \& Rivera-González, M. (2011). Interpretación del cambio en vegetación y uso de suelo. 2011. Terra Latinoamericana, 29(4), 359-367.

USGS - United States Geological Survey. (2018). Earth Explorer. https://earthexplorer.usgs.gov/

Villalta, C., \& Castaneda, L. (2003). Manual de manejo de cuencas hidrográficas. Universidad de El Salvador, Facultad de Ciencias Agronómicas.

Vuille, M. (2013). El cambio climático y los recursos hídricos en los Andes tropicales (Nota Técnica IDB-TN-517). Banco Interamericano de Desarrollo, Unidad de Salvaguardias Ambientales. 
Weber, H. E., Moravec, J., \& Theurillat, J. P. (2000). International Code of Phytosociological Nomenclature. Journal of Vegetation Science, 11, 739-768. https://doi.org/10.2307/3236580

Yallico, E. (1992). Distribución de Polylepis en el sur de Puno. Puno, Perú: Proyecto Arbolandino, Apoyo al Desarrollo Forestal Comunal de la Región Altoandina.

Yan, X., Li, J., \& Yang, Z. (2018). Analysis on temporal-spatial changes of vegetation Cverrge in farming-pastoral ecotone of inner Mongolia. The International
Archives of the Photogrammetry, Remote Sensing and Spatial Information Sciences, 42(3), 2053-2057. https://doi.org/10.5194/ isprs-archives-XLII-3-2053-2018

Yaranga, R., Custodio, M., Chanamé, F., \& Pantoja, R. (2018). Diversidad florística de pastizales según formación vegetal en la subcuenca del río Shullcas, Junín, Perú. Scientia Agropecuaria, 9(4), 511-517. https://doi.org/10.17268/ sci.agropecu.2018.04.06

\section{(c) $($ i) $(9)$}

Análisis multitemporal de asociaciones vegetales y cambios de uso del suelo en una localidad altoandina, Puno-Perú (Alfredo Loza-Del Carpio • Irene Taype-Huamán) Uniciencia is protected by Attribution-NonCommercial-NoDerivs 3.0 Unported (CC BY-NC-ND 3.0) 